\title{
Differences in Primary Care Appointment Availability and Wait Times by Neighborhood Characteristics: a Mystery Shopper Study
}

\author{
David Grande, MD, MPA ${ }^{1,2}$, Jessica X. Zuo, BA ${ }^{3}$, Rathnam Venkat, $B A^{4}$, Xinwei Chen, $M S^{7}$, \\ Katelyn R. Ward, $B A^{5}$, Jane W. Seymour, $M P H^{6}$, and Nandita Mitra, $P h D^{7}$
}

\begin{abstract}
'Division of General Internal Medicine, Perelman School of Medicine, University of Pennsylvania, Philadelphia, PA, USA; ${ }^{2}$ Leonard Davis Institute of Health Economics, Perelman School of Medicine, University of Pennsylvania, Philadelphia, PA, USA; ${ }^{3}$ Perelman School of Medicine, University of Pennsylvania, Philadelphia, PA, USA; ${ }^{4}$ Wharton School, University of Pennsylvania, Philadelphia, PA, USA; ${ }^{5}$ Tufts University School of Medicine, Boston, MA, USA; ${ }^{6}$ Department of Epidemiology, Boston University School of Public Health, Boston, MA, USA; ' Department of Biostatistics and Epidemiology, Perelman School of Medicine, University of Pennsylvania, Philadelphia, PA, USA.
\end{abstract}

KEY WORDS: primary care access; simulated patient; primary care supply; appointment availability; appointment wait times.

J Gen Intern Med 33(9):1441-3

DOI: $10.1007 / \mathrm{s} 11606-018-4407-9$

(c) Society of General Internal Medicine 2018

\section{INTRODUCTION}

Primary care is widely recognized as a gateway to the health care system and improved health. ${ }^{1}$ Prior studies have found disparities in appointment access by insurance type $^{2}$ (commercial vs. Medicaid) and mixed findings on the association of neighborhood socioeconomic status and having a usual source of care. ${ }^{3,4}$ We previously found large racial differences in the supply of primary care across neighborhoods in a large urban area (Philadelphia, PA). ${ }^{5}$ In this study, we examine how appointment access varies by neighborhood socio-demographics and primary care supply-hypothesizing less access in low SES neighborhoods and those with lower supply.

\section{METHODS}

As previously described, we inventoried adult primary care practices in and near Philadelphia County. ${ }^{5}$ From July 6 to September 14, 2015, research assistants posing as patients called practices to request a new, non-urgent, appointment. ${ }^{2}$ Medicaid participating practices received private and Medicaid-insured calls. Practices were excluded if they did not offer primary care $(n=16)$, had a disconnected phone $(n=$ $17)$, or served a specialized population $(n=16)$ (e.g., university student health center). The University of Pennsylvania Institutional Review Board approved this study.

We used the American Community Survey (2008-2013) to determine characteristics of census tracts and tract-level population-to-provider ratios for adult primary care. ${ }^{5}$ We used a relative measure of low primary care access ${ }^{5}$; clusters of five or more contiguous census tracts in the lowest quintile for primary care supply.

Published online June 4, 2018

\section{Analyses}

We defined availability and wait times as whether an appointment was offered (binary) and the number of days from the request to the appointment offered (continuous), respectively. We modeled the association of availability with census tract characteristics and our measure of low primary care supply using a multi-level random intercept logistic mixed effects model with clustering at the clinic and census tract levels. A linear mixed effects model was similarly used to examine wait times.

\section{RESULTS}

\section{Practice Sample}

We identified 399 practices in the study area -276 accepted Medicaid and private insurance, 111 accepted only private insurance, and 12 were only reached by our Medicaid callers. We excluded 12 due to inability to complete scheduling.

\section{Appointment Availability}

Callers were offered an appointment in $79 \%$ of the calls; fewer Medicaid callers received appointments than those with private insurance ( 68 vs. $87 \%$; OR $=0.32 ; 95 \%$ $\mathrm{CI}=0.21-0.47)$. There were no differences in appointment availability for privately insured callers at Medicaid participating vs. non-participating practices. Practices' census tract characteristics were not associated with appointment availability except for the uninsured rate (Table 1). Offices in census tracts with high rates $(\geq 30 \%)$ of uninsurance were less likely to offer appointments $(\mathrm{OR}=$ $0.24 ; 95 \% \mathrm{CI}=0.07-0.90)$. There was no association with location in a lower primary care supply area.

\section{Appointment Wait Time}

The median appointment wait time was 10 days (IQR $=4-21)$. Wait times were similar $(p=0.29)$ for Medicaid-insured (median $=12.5, \mathrm{IQR}=5-25.5$ ) and privately insured callers (median $=9, \mathrm{IQR}=4-20$ ). Findings were similar when the sample 
Table 1 Appointment Availability by Census Tract Characteristics of Primary Care Practices

\begin{tabular}{|c|c|c|c|c|c|}
\hline $\begin{array}{l}\text { Census tract characteristics of } \\
\text { primary care practices }\end{array}$ & $\begin{array}{l}\text { \% offered an } \\
\text { appointment }\end{array}$ & $\begin{array}{l}\text { Unadjusted odds } \\
\text { ratio }\end{array}$ & $\begin{array}{l}P \text { value for } \\
\text { unadjusted ORs }\end{array}$ & $\begin{array}{l}\text { Adjusted odds ratio* } \\
(95 \% \mathrm{CI})^{1}\end{array}$ & $\begin{array}{l}P \text { value for } \\
\text { AORs }\end{array}$ \\
\hline \multicolumn{6}{|l|}{$\%$ population with public insurance } \\
\hline$<10 \%$ & $77 \%$ & Ref & _- & Ref & _- \\
\hline $10-19 \%$ & $82 \%$ & $1.40(0.83,2.38)$ & 0.21 & $1.32(0.53,3.29)$ & 0.55 \\
\hline $20-29 \%$ & $75 \%$ & $0.89(0.53,1.51)$ & 0.68 & $0.83(0.29,2.43)$ & 0.74 \\
\hline$\geq 30 \%$ & $80 \%$ & $1.19(0.70,2.00)$ & 0.52 & $1.18(0.35,4.05)$ & 0.79 \\
\hline \multicolumn{6}{|l|}{$\%$ population that is uninsured } \\
\hline$<10 \%$ & $82 \%$ & Ref & - & Ref & - \\
\hline $10-19 \%$ & $78 \%$ & $0.79(0.43,1.44)$ & 0.45 & $0.46(0.17,1.25)$ & 0.13 \\
\hline $20-29 \%$ & $80 \%$ & $0.88(0.48,1.62)$ & 0.68 & $0.45(0.15,1.33)$ & 0.15 \\
\hline \multirow{2}{*}{\multicolumn{6}{|c|}{ poverty level of population }} \\
\hline & & & & & \\
\hline$<100 \%$ & $74 \%$ & Ref & - & Ref & - \\
\hline $100-200 \%$ & $82 \%$ & $1.56(0.96,2.53)$ & 0.07 & $2.04(0.87,4.80)$ & 0.10 \\
\hline$>200 \%$ & $76 \%$ & $1.13(0.67,1.92)$ & 0.65 & $1.27(0.43,3.80)$ & 0.67 \\
\hline \multicolumn{6}{|l|}{$\%$ population that is Black } \\
\hline$<20 \%$ & $78 \%$ & Ref & - & Ref & - \\
\hline $20-79 \%$ & $77 \%$ & $0.94(0.62,1.42)$ & 0.76 & $1.16(0.60,2.26)$ & 0.66 \\
\hline$\geq 80 \%$ & $85 \%$ & $1.58(0.90,2.77)$ & 0.11 & $2.60(0.87,7.78)$ & 0.09 \\
\hline \multicolumn{6}{|l|}{$\overline{\%}$ population that is Hispanic } \\
\hline $5-10 \%$ & $84 \%$ & $1.4(0.85,2.31)$ & $\overline{0} .19$ & $2.06(0.99,4.29)$ & $\overline{0} .05$ \\
\hline $10-20 \%$ & $72 \%$ & $0.7(0.41,1.19)$ & 0.19 & $1.13(0.46,2.76)$ & 0.79 \\
\hline$>20 \%$ & $77 \%$ & $0.87(0.52,1.48)$ & 0.62 & $1.82(0.65,5.10)$ & 0.25 \\
\hline \multicolumn{6}{|l|}{ Low access area } \\
\hline No & $78 \%$ & Ref & _- & Ref & _- \\
\hline Yes & $83 \%$ & $1.35(0.64,2.84)$ & 0.43 & $1.07(0.4,2.84)$ & 0.90 \\
\hline
\end{tabular}

${ }^{I}$ Adjusted for clinic census tract characteristics in table as well as American Community Survey (ACS) median age, insurance type of caller, FQHC status, and practice size

was restricted to the primary care offices that accepted both types of insurance and when stratifying practices by insurance participation (both vs. Medicaid only). Practices' census tract characteristics were not associated with wait times (Table 2). Wait times were similar regardless of whether or not a practice was located in an area of lower primary care supply.

\section{DISCUSSION}

In this large urban area, we found differences in new appointment availability by insurance type with a magnitude similar to prior studies. ${ }^{2}$ However, availability and wait times were not associated with neighborhood socio-demographic

Table 2 Wait Time by Census Tract Characteristics of Primary Care Practices

\begin{tabular}{|c|c|c|c|c|c|}
\hline $\begin{array}{l}\text { Census tract characteristics } \\
\text { of primary care practices }\end{array}$ & $\begin{array}{l}\text { Unadjusted median } \\
\text { wait time (IQR) }\end{array}$ & $\begin{array}{l}\text { Unadjusted } \\
\text { average wait time }\end{array}$ & $\begin{array}{l}\text { Unadjusted \% change } \\
\text { in wait time }(95 \% \mathrm{CI})\end{array}$ & $\begin{array}{l}\text { Adjusted \% change in } \\
\text { wait time }^{1}(95 \% \mathrm{CI})\end{array}$ & $P$ value ${ }^{2}$ \\
\hline \multicolumn{6}{|c|}{$\%$ population with public insurance } \\
\hline$<10 \%$ & $8(4,16)$ & 17.8 & Ref & - & - \\
\hline $10-19 \%$ & $12(4,22)$ & 17.5 & $18(-19.4,72.1)$ & $16(-31.2,94)$ & 0.58 \\
\hline $20-29 \%$ & $12(5,28)$ & 19.4 & $21(-20.9,83.9)$ & $3(-44.1,91.6)$ & 0.91 \\
\hline$\geq 30 \%$ & $12(5,22)$ & 16.5 & $13(-23.4,66.4)$ & $-7(-53.5,87)$ & 0.84 \\
\hline \multicolumn{6}{|l|}{$\overline{\%}$ population that is uninsured } \\
\hline $10-19 \%$ & $10(4,22)$ & $\begin{array}{l}10.2 \\
17.5\end{array}$ & $\begin{array}{l}\text { Ret } \\
9(-27.4,64.6)\end{array}$ & $\overline{9}(-35.9,86.6)$ & $\overline{0} .74$ \\
\hline $20-29 \%$ & $12(4,21)$ & 17.1 & $15(-24.2,73.4)$ & $8(-40.2,95.9)$ & 0.79 \\
\hline$\geq 30 \%$ & $15(5,32)$ & 25.4 & $56(-18.3,197)$ & $49(-33.6,232.2)$ & 0.33 \\
\hline \multicolumn{6}{|l|}{ Poverty level of population } \\
\hline$<100 \%$ & $13(6,23)$ & 16.7 & Ref & - & - \\
\hline $100-200 \%$ & $10.5(4,27)$ & 18.9 & $-14(-41.1,25.8)$ & $-16(-47.6,35.4)$ & 0.48 \\
\hline$>200 \%$ & $8(4,15)$ & 15.7 & $-24(-49.9,15)$ & $-22(-58.1,43.7)$ & 0.42 \\
\hline \multicolumn{6}{|l|}{$\%$ population that is Black } \\
\hline $20-79 \%$ & $11(5,27)$ & 18.3 & $15(-17.1,58.9)$ & $3(-29.6,51.7)$ & 0.87 \\
\hline$\geq 80 \%$ & $12(4,21)$ & 15.5 & $-7(-35.9,35.9)$ & $-19(-56.5,52.1)$ & 0.52 \\
\hline \multicolumn{6}{|l|}{$\overline{\%}$ population that is Hispanic } \\
\hline$<5 \%$ & $11(4,22)$ & 16.8 & Ref & - & - \\
\hline $5-10 \%$ & $11.5(5,20)$ & 17.6 & $3(-27.6,45.2)$ & $-8(-38.4,37.6)$ & 0.68 \\
\hline $10-20 \%$ & $9(3,22)$ & 17.9 & $1(-34.3,56.0)$ & $-15(-50.4,45.8)$ & 0.55 \\
\hline$>20 \%$ & $10(5.5,28)$ & 20.0 & $22(-20.2,85.1)$ & $-6(-49.7,74.3)$ & 0.83 \\
\hline \multicolumn{6}{|l|}{ Low access area } \\
\hline No & $11(4,21)$ & 18.0 & Ref & - & - \\
\hline Yes & $8(4,15)$ & 11.2 & $-20(-52.9,34.7)$ & $-17(-52.8,47.8)$ & 0.53 \\
\hline
\end{tabular}

${ }^{1}$ Adjusted for clinic census tract characteristics in table as well as census tract median age, insurance type of caller, FQHC status of practice, and practice size

${ }^{2} P$ values are for log-transformed wait times 
characteristics or the supply of nearby primary care except for the uninsurance rate. The lack of an association with primary care supply could be explained by patient travel patterns for care or if supply is adequate to meet population demand even in lower supply areas.

Our study has several limitations: simulated patients may represent a "best-case" scenario compared to patients unaccustomed to navigating health care, our methods do not address patient preferences for providers or planspecific networks, our study was in a single city with a high provider density, and we were unable to account for practice characteristics such as panel size or "no-show" rates and their impact on practice scheduling systems. Future studies should examine the relationship between primary care supply and appointment access in other settings and seasons to determine the conditions under which decreased supply leads to differences in appointment access.

Acknowledgements: The authors thank Daniel Polsky and Karin Rhodes for their contributions to the study design and review of prior versions of the study manuscript and Ashley Beggin for assisting with data analysis and critical revisions of the manuscript.

Corresponding Author: David Grande, MD, MPA; Division of General Internal Medicine, Perelman School of Medicine University of
Pennsylvania, Philadelphia, PA, USA (e-mail: dgrande@wharton. upenn.edu).

\section{Compliance with ethical standards:}

Funding information: Funding for this study was provided by the Independence Foundation in Philadelphia, PA.

Prior presentations: Some preliminary results from this study were presented at 1) the June, 2016 Academy Health Annual Meeting in Boston, MA and 2) the May, 2016 SGIM Annual Meeting in Hollywood, FL.

Conflict of interest: The authors declare that they do not have a conflict of interest.

\section{REFERENCES}

1. Starfield B, Shi L, Macinko J. Contribution of primary care to health systems and health. Milbank Q. 2005;83(3):457-502.

2. Polsky D, Candon M, Saloner B, Wissoker D, Hempstead K, Kenney GM, Rhodes K. Changes in primary care access between 2012 and 2016 for new patients with Medicaid and private coverage. JAMA Intern Med. 2017; 177(4):588-590.

3. Kirby JB, Kaneda T. Neighborhood socioeconomic disadvantage and access to health care. J Health Soc Behav. 2005;46(1):15-31.

4. Hussein M DRA, Field RI. Neighborhood socioeconomic status and primary health care: Usual points of access and temporal trends in a major US urban area. J Urban Health. 2016;93(6): 1027-1045.

5. Brown EJ, Polsky D, Barbu CM, Seymour JW, Grande D. Racial Disparities In Geographic Access To Primary Care In Philadelphia. Health Aff (Millwood). 2016;35(8):1374-1381. 